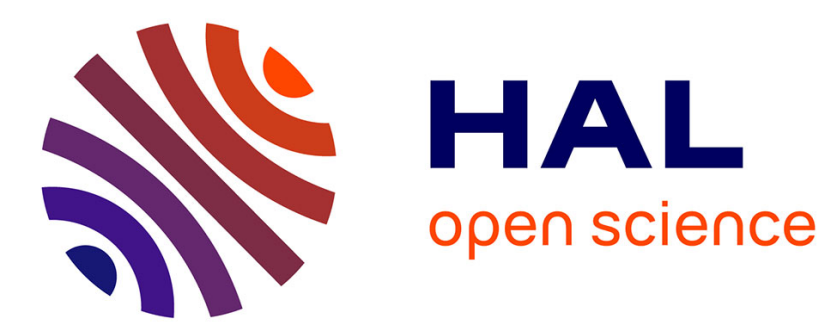

\title{
Bromine polycondensation in pristine and fluorinated graphitic carbons
}

\author{
Olga Sedelnikova, Christopher Ewels, Dmitry Pinakov, Galina Chekhova, \\ Emmanuel Flahaut, Alexander Okotrub, Lyubov Bulusheva
}

\section{To cite this version:}

Olga Sedelnikova, Christopher Ewels, Dmitry Pinakov, Galina Chekhova, Emmanuel Flahaut, et al.. Bromine polycondensation in pristine and fluorinated graphitic carbons. Nanoscale, 2019, 11 (32), pp.15298-15306. 10.1039/c9nr01922g · hal-02301196

\section{HAL Id: hal-02301196 https://hal.science/hal-02301196}

Submitted on 1 Oct 2019

HAL is a multi-disciplinary open access archive for the deposit and dissemination of scientific research documents, whether they are published or not. The documents may come from teaching and research institutions in France or abroad, or from public or private research centers.
L'archive ouverte pluridisciplinaire HAL, est destinée au dépôt et à la diffusion de documents scientifiques de niveau recherche, publiés ou non, émanant des établissements d'enseignement et de recherche français ou étrangers, des laboratoires publics ou privés. 


\section{OATAO \\ Open Archive Toulouse Archive Ouverte}

\section{Open Archive Toulouse Archive Ouverte (OATAO)}

OATAO is an open access repository that collects the work of Toulouse researchers and makes it freely available over the web where possible

This is an author's version published in: http://oatao.univ-toulouse.fr/24316

Official URL: https://doi.org/10.1039/c9nr01922g

\section{To cite this version:}

Sedelnikova, Olga V. and Ewels, Christopher P. and Pinakov, Dmitry V. and Chekhova, Galina N. and Flahaut, Emmanuel $\stackrel{\varpi}{\leftrightarrows}$ and Okotrub, Alexander V. and Bulusheva, Lyubov G. Bromine polycondensation in pristine and fluorinated graphitic carbons. (2019) Nanoscale, 11 (32). 15298-15306. ISSN 2040-3364

Any correspondence concerning this service should be sent to the repository administrator: tech-oatao@listes-diff.inp-toulouse.fr 


\title{
Bromine polycondensation in pristine and fluorinated graphitic carbons $\uparrow$
}

\author{
Olga V. Sedelnikova, (D)*a,b Christopher P. Ewels, (D)*c Dmitry V. Pinakov, (D) a,b \\ Galina N. Chekhova, ${ }^{a}$ Emmanuel Flahaut, (D) d,e Alexander V. Okotrub (iD ${ }^{\text {a,b }}$ and \\ Lyubov G. Bulusheva (D) a,b
}

\begin{abstract}
Despite decades of study the precise behavior of bromine in graphitic carbons remains unclear. In this report, using Raman spectroscopy, we reveal two types of bromine structure in graphitic carbon materials. Between fluorinated graphene layers with a composition close to $\mathrm{C}_{2} \mathrm{~F}, \mathrm{Br}_{2}$ molecules are intercalated in a form similar to liquid bromine. Bromination of pristine and low-fluorinated graphitic carbons behaves very differently with distinct Br-related Raman spectra. With the guidance of density functional theory (DFT) calculations, all Raman features are assigned to normal vibration modes of specific bromine species over graphene and fluorinated graphene. When intercalated between extended non-fluorinated $\mathrm{sp}^{2}$-hybridized carbon regions, physisorbed $\mathrm{Br}_{2}$ molecules move freely across the non-functionalized region toward the $\mathrm{CF}$ border. Multiple $\mathrm{Br}_{2}$ molecules then combine spontaneously into $\mathrm{Br}_{3}$-based chains, whose coupling activates otherwise Raman inactive modes. Significant charge transfer to bromine species occurs in this case. DFT calculated frequencies match precisely the experimental Br-related Raman bands observed in the intercalation carbon compounds. The fluorine-catalyzed bromine chain-formation process shown here is general and should also operate with edges and other defect species.
\end{abstract}

\section{Introduction}

Among different methods of chemical modification of carbon, halogenation is one of the most promising. Fluorination and bromination can be used to obtain graphene precursor materials and for the individualization of carbon nanotubes (CNTs). This is due to the halogen intercalant layers reducing the $\pi-\pi$ interactions between the layers in graphite and the CNTs in bundles. ${ }^{1-4}$ Previously we have shown that the fluorine pattern on the surface of double-walled CNTs (DWCNTs) depends on the fluorination method. ${ }^{5,6}$ In particular, roomtemperature fluorination with $\mathrm{BrF}_{3}$ mostly produces short fluorinated chains with CF bonds. Partially fluorinated graphite with a stoichiometry close to $\mathrm{C}_{2} \mathrm{~F}$ has a patchwork fluorine pattern on the basal planes composed of non-fluorinated gra-

\footnotetext{
${ }^{a}$ Nikolaev Institute of Inorganic Chemistry SB RAS, 3 Academician Lavrentiev Av., Novosibirsk 630090, Russian Federation. E-mail: o.sedelnikova@gmail.com

${ }^{b}$ Novosibirsk State University, 2 Pirogov Str., Novosibirsk 630090, Russian Federation ${ }^{c}$ Institut des Matériaux Jean Rouxel, CNRS-Université de Nantes, UMR6502,

2 Rue de la Houssinière, BP32229, 44322 Nantes cedex 3, France.

E-mail: chris.ewels@cnrs-imn.fr

${ }^{d}$ Université de Toulouse, UPS, INP, Institut Carnot Cirimat, 118, route de Narbonne, F-31062 Toulouse cedex 9, France

${ }^{e}$ CNRS, Institut Carnot Cirimat, F-31062 Toulouse, France

$\dagger$ Electronic supplementary information (ESI) available. See DOI: 10.1039/ c9nr01922g
}

phene nanoregions, which are separated by $\mathrm{sp}^{3}$-hybridized carbon atoms bonded to zigzag fluorine chains. ${ }^{6-10}$ Covalent functionalization of the carbon surface can drastically change the electronic structure of the material. Fluorination of graphite layers and metallic CNTs opens a band gap, which can be tuned by tailoring the content and distribution of fluorine. ${ }^{11-13}$

Bromine has a lower electronegativity than fluorine and bromination of graphite and CNTs usually results in an adsorption of bromine species, ${ }^{4,14}$ although covalent bonding between bromine and carbon atoms is also possible. ${ }^{4,15,16}$ Ionic bromine doping enhances the conductivity of graphite, graphene, and CNTs ${ }^{4,17-20}$ improving their electrochemical properties in Li-ion batteries ${ }^{21}$ and gas sensor efficiency. ${ }^{22}$ Bromine forms layers between the graphite sheets that promotes isolation of monolayers. ${ }^{1-3}$ Similarly bromine can intercalate between CNTs in bundles, helping to separate them. ${ }^{4}$ Moreover, bromination of CNTs can assist in the separation of metallic and semiconducting nanotubes. ${ }^{23}$

Graphite-bromine compounds have been studied over many decades. ${ }^{17,24-30}$ The structure of the bromine layers is still widely debated. The pioneering works of Eeles and Turnbull, ${ }^{24}$ Sasa et $a l_{.}{ }^{25}$ and Eklund et $a l_{.}{ }^{26}$ reported formation of $\mathrm{Br}_{2}$ chains with an interatomic distance close to that in solid bromine. Ghosh and Chung however suggested organization of long-chain polymeric bromine anions. ${ }^{27}$ Formation of poly- 
bromide compounds has been detected in activated carbon material, possessing a diamond-like structure with embedded graphene regions. ${ }^{31}$ Some reports have suggested a possibility of stabilizing $\mathrm{Br}_{3}{ }^{-}$and $\mathrm{Br}_{5}{ }^{-}$polyanions in bromine intercalated $\mathrm{CNTs}^{4,14,32-36}$ similar to observed polyiodide structures. ${ }^{37,38}$ The formation of bromine chains has also been observed inside the one-dimensional channels of zeolite crystals. ${ }^{39}$ This process originates from the charge transfer between guest species and the crystal. Since bromine acts as an electron acceptor for the $\mathrm{sp}^{2}$-hybridized carbon surface, its polymerization over this surface is plausible.

Co-functionalization of graphite and CNTs with fluorine and bromine is of interest due to an interplay between the band gap opening and metallization effects in the materials. However, to the best of our knowledge, bromination behaviour in fluorinated carbon materials has never been discussed. In this paper, we investigate the peculiarities of bromination of pristine and partially fluorinated graphite and DWCNTs using Raman spectroscopy and density functional theory (DFT) calculations. By increasing the fluorine content in fluorinated graphite $\mathrm{C}_{2} \mathrm{~F}_{x}$ with $0.07<x<0.94$, we reduce the size of nonfunctionalised graphene nanoregions and study how this affects the bromination process. Based on DFT calculated $\mathrm{Br}-$ $\mathrm{Br}$ vibrational frequencies, we reveal two distinct intercalated bromine species and propose bromination mechanisms of fluorinated carbons depending on the fluorination level.

\section{Experimental section}

\section{Experimental methods}

Natural graphite from the Zavalievo deposit (Ukraine) was used as starting material to synthesize graphite intercalation compound and fluorinated graphite intercalation compounds with bromine. Bromination of graphite was performed in a Teflon flask in saturated $\mathrm{Br}_{2}$ vapour for 2 days at room temperature. The fresh sample is the second-stage intercalation compound $\mathrm{C}_{8} \mathrm{Br}$. When stored under normal conditions, the compound loses the intercalated bromine to the composition of $\mathrm{C}_{24} \mathrm{Br}^{40}$ Such material is denoted $\mathrm{G}-\mathrm{Br}$ in this communication.

To obtain fluorinated graphite intercalation compounds with bromine, we use a procedure described elsewhere. ${ }^{9,41,42}$ Briefly, just obtained $\mathrm{C}_{8} \mathrm{Br}$ sample was placed in another Teflon flask in vapour over a solution of $\mathrm{BrF}_{3}$ in $\mathrm{Br}_{2}$ at room temperature. The obtained fluorinated graphite materials are the first-stage intercalation compounds with $\mathrm{Br}_{2}$ and $\mathrm{BrF}_{3}$ components. The fluorine content in the product is controlled by changing the $\mathrm{BrF}_{3}$ concentration from 1 to 12 vol\% in $\mathrm{Br}_{2}$ and the synthesis duration from 1 month to 4 months. At the final stage, the samples were held in saturated $\mathrm{Br}_{2}$ vapour for 2 days. For complete replacement of $\mathrm{BrF}_{3}$ by $\mathrm{Br}_{2}$, the process was repeated 5 times for all samples. Hereafter the fluorinated graphite intercalated compounds are referred to as $\mathrm{C}_{2} \mathrm{~F}_{x}$-Br.

Elemental analysis of the samples was performed as following. The content of carbon was determined by CHNS ana- lysis. ${ }^{43}$ A portion of a sample (3-5 $\mathrm{mg}$ ) was combusted in an oxygen flow at $900-950{ }^{\circ} \mathrm{C}$. The pyrolysis products were then oxidized and halogens $(\mathrm{F}, \mathrm{Br})$ were adsorbed on the $\mathrm{ZrO}_{2}$ $\mathrm{MgO}-\mathrm{AgWO}_{4}$ composite system at $750{ }^{\circ} \mathrm{C}$. The resulting $\mathrm{CO}_{2}$ content was determined by thermogravimetric analysis. The total contents of fluorine and bromine was determined using the Shöniger method. ${ }^{44}$ A portion of a sample (1-3 mg) was decomposed at $1300-1400{ }^{\circ} \mathrm{C}$ in a flask filled with oxygen. Pt catalyst and special additives were used in order to improve the combustion. The resultant product contains bromine and fluorine ions. The concentration of bromine was determined by the mercurimetric titration of as-obtained solution in acid medium in the presence of diphenylcarbazone indicator. The concentration of fluorine was determined spectrophotometrically via formation of a lanthanum/alizarin complex. Together these methods allow quantification of carbon, fluorine, and bromine concentration with an accuracy of $0.5,1.5$, and $2.0 \%$, respectively.

Raman scattering spectra were recorded on a LabRAM HR Evolution (Horiba) spectrometer using a $514 \mathrm{~nm}$ excitation. The spectra recorded at room temperature were normalized with respect to the peak with maximal intensity and are displayed with a slight offset for clarity.

\section{Experimental results}

A study of four $\mathrm{C}_{2} \mathrm{~F}_{x}$-Br samples obtained under different conditions using elemental analysis revealed the compositions $\mathrm{C}_{2} \mathrm{~F}_{0.94} \cdot \mathrm{Br}_{0.22}, \mathrm{C}_{2} \mathrm{~F}_{0.47} \cdot \mathrm{Br}_{0.14}, \mathrm{C}_{2} \mathrm{~F}_{0.24} \cdot \mathrm{Br}_{0.08}$, and $\mathrm{C}_{2} \mathrm{~F}_{0.07} \cdot \mathrm{Br}_{0.06}$. The sample $\mathrm{G}-\mathrm{Br}$ can be written as $\mathrm{C}_{2} \cdot \mathrm{Br}_{0.08}$.

Raman spectra of $\mathrm{G}-\mathrm{Br}$ and $\mathrm{C}_{2} \mathrm{~F}_{x}-\mathrm{Br}$ samples show two regions related to vibrations of the host matrix (1250-2000 $\mathrm{cm}^{-1}$ ) and intercalated species $\left(100-590 \mathrm{~cm}^{-1}\right.$, Fig. 1), respectively. In the first region, the spectra of $\mathrm{C}_{2} \mathrm{~F}_{x}-\mathrm{Br}$ samples contains D and $\mathrm{G}$ bands located at 1361 and $1597 \mathrm{~cm}^{-1}$ characteristic of $\mathrm{sp}^{2}$-hybridized carbon with disorder produced by covalent fluorine attachment. ${ }^{45}$ The D band intensity increases with degree of fluorination. Due to the high quality of the starting natural graphite, the $\mathrm{D}$ band is absent in the spectrum of $\mathrm{G}-\mathrm{Br}$ sample and the $\mathrm{G}$ band has a double structure with peaks at 1584 and $1602 \mathrm{~cm}^{-1}$. These peaks correspond to the lattice vibrations of the graphite layers without bromine species between them and those adjacent to an intercalated bromine layer, respectively.

From 100 to $600 \mathrm{~cm}^{-1}$ the Raman spectrum of $\mathrm{C}_{2} \mathrm{~F}_{0.94}-\mathrm{Br}$ (hereinafter referred to as highly fluorinated graphite) resembles the spectrum of liquid bromine, in agreement with a previous study of similar samples. ${ }^{46} \mathrm{~A}$ single peak at $c a$. $311 \mathrm{~cm}^{-1}$ (denoted IV') is located between the peaks of solid bromine $\left(296 \mathrm{~cm}^{-1}\right)^{47}$ and gaseous bromine $\left(323 \mathrm{~cm}^{-1}\right) .{ }^{48} \mathrm{In}$ contrast, the spectra of $\mathrm{C}_{2} \mathrm{~F}_{x}$-Br samples with $x=0.47,0.24$, 0.07 (hereinafter referred as low-fluorinated compounds) and $\mathrm{G}-\mathrm{Br}$ have a rich structure. The peak at ca. 235-239 $\mathrm{cm}^{-1}$ (denoted III) and its overtone at $c a .472-474 \mathrm{~cm}^{-1}$ (denoted VI) are usually assigned to the $\mathrm{Br}-\mathrm{Br}$ stretching of intercalated $\mathrm{Br}_{2}$ molecules. $^{4,14,26,28-30,35,49}$ There are also peaks at ca. 155-158 $\mathrm{cm}^{-1}$ (denoted I), previously assigned to chain-like 


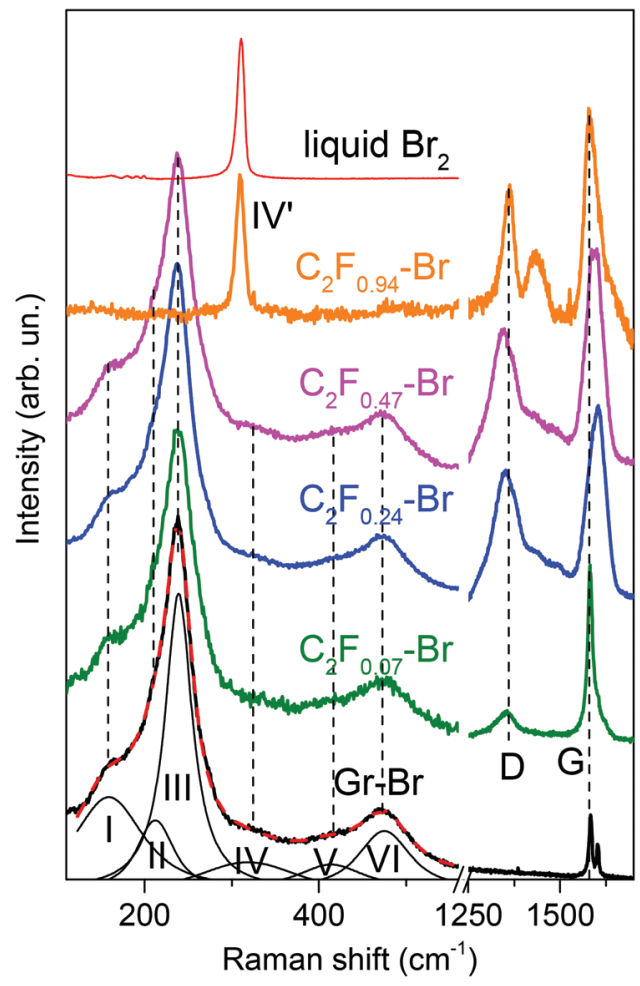

Fig. 1 Raman spectra taken at $514 \mathrm{~nm}$ for $\mathrm{G}-\mathrm{Br}$ and $\mathrm{C}_{2} \mathrm{~F}_{x}-\mathrm{Br}$ compounds in comparison with a reference spectrum of liquid bromine. Dashed lines indicate positions of Raman peaks denoted as I-VI, D, and $\mathrm{G}$. Deconvolution shown on the example of $\mathrm{G}-\mathrm{Br}$ spectrum, where the peaks (thin lines) were described by Voigt functions.

polybromine anions,${ }^{14}$ as well as $200-212 \mathrm{~cm}^{-1}$ (denoted II), $318-328 \mathrm{~cm}^{-1}$ (denoted IV), and $407-413 \mathrm{~cm}^{-1}$ (denoted V). The latter can be assigned as a combination of I and III modes. We note that the Br-related Raman spectra are almost the same for the samples with zero and low-fluorination levels. This can be understood from the heterogeneous distribution of fluorine patterning of graphene planes, ${ }^{9,10,50-53}$ indicating that the bromine signal is coming from species adsorbed on the non-fluorinated regions.

\section{Simulations}

DFT calculations were invoked to study the electronic structure and normal vibration modes of bromine species over graphene and fluorinated graphene layers, in order to understand origin of the bromine-related peaks in the Raman spectra of G-Br and $\mathrm{C}_{2} \mathrm{~F}_{x}$ - $\mathrm{Br}$ samples.

\section{Calculation details}

To investigate interaction between $\mathrm{Br}_{2}, \mathrm{Br}_{3}$, and $\mathrm{Br}_{6}$ with graphene, we used a hexagonal $11 \times 11$ supercell of graphene composed of 242 carbon atoms (Fig. S1 $\dagger$ ). The separation between slabs was $15 \AA$. Experimental investigations of fluorinated graphene showed that fluorine atoms form localized regions, which grow with an increase of the fluorination level. ${ }^{6-10}$ At low coverage, recent first-principle calculations demonstrated the tendency of stripe-like patterns to form along armchair and zigzag directions. ${ }^{54}$ Therefore to simulate substrates of fluorinated graphene and its interface with bromine, we considered zigzag chains of fluorinated carbon atoms alternated with 10 chains of bare $\mathrm{sp}^{2}$-hybridized carbon atoms. Following previous literature, ${ }^{6-8,54}$ fluorine atoms were sequentially attached to alternating sides of the graphene sheet. Although the perpendicular orientation of $\mathrm{Br}_{2}$ relative to graphene and fluorinated graphene is slightly energetically preferable, ${ }^{55}$ hereafter the properties of $\mathrm{Br}_{2}$ lying parallel to the sheet will be discussed since this configuration is expected for the intercalation compounds. Bromine species were positioned either above the centre of the graphene supercell (see ESI $\dagger$ ) or near to the fluorine boundary (Fig. 2).

Accurate prediction of binding energies between substrate and physisorbed molecules is a challenging task, especially in extended low-dimension systems. However, while the local density approximation (LDA) does not include dispersion corrections, the over-binding presented in the method is able to compensate this in a large extent. Thereby weak interactions are reproduced rather correctly within LDA approximation. The one example is graphite, where the LDA reproduces with reasonable accuracy both the interlayer spacing and binding energy. ${ }^{56}$ This method gives also correct interaction energies of water and

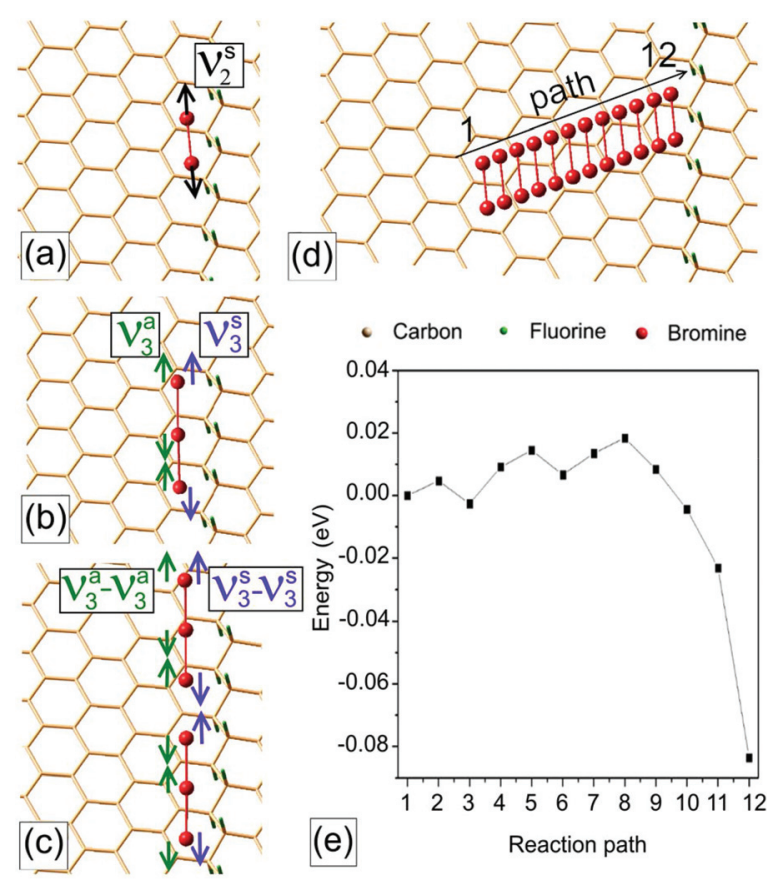

Fig. 2 Fragments of fluorinated graphene with adsorbed $\mathrm{Br}_{2}(\mathrm{a}), \mathrm{Br}_{3}$ (b) and $\mathrm{Br}_{6}$ (c) species. Arrows indicate the directions of atomic motion for normal stretching modes of $\mathrm{Br}_{2}\left(\nu_{2}{ }^{\mathrm{s}}\right), \mathrm{Br}_{3}\left(\nu_{3}{ }^{\mathrm{a}}\right.$ and $\left.\nu_{3}{ }^{\mathrm{s}}\right)$, and $\mathrm{Br}_{6}\left(\nu_{3}{ }^{\mathrm{a}}-\nu_{3}{ }^{\mathrm{a}}\right.$ and $\left.\nu_{3}{ }^{\mathrm{s}}-\nu_{3}^{\mathrm{s}}\right)$. Diffusion path of $\mathrm{Br}_{2}$ over partially fluorinated graphene layer from the non-fluorinated area (position 1) to the fluorine chain (position 12) (d). NEB path was constructed automatically from position 1 to 12. Diffusion barrier of $\mathrm{Br}_{2}$ over partially fluorinated graphene (e). 
hydrogen inside CNTs and on graphene. ${ }^{57}$ Moreover, Raman spectra are directly related to near-interatomic forces, which are mainly governed by covalent interactions, which are generally well accounted by LDA. Due to the well-known compensation effect between the overestimated interatomic forces and the underestimated bond lengths, the LDA was chosen for investigation of electronic and phonon properties of graphene and fluorinated graphene with adsorbed bromine species.

All calculations were carried out with the AIMPRO code. ${ }^{5-60}$ This method has been successfully used for the study of intercalated boron in graphite. ${ }^{5,61}$ For $\mathrm{C} / \mathrm{F} / \mathrm{Br}$, basis sets containing 22/28/50 independent Gaussian-based functions were used. Core electrons were eliminated using normconserving relativistic pseudopotentials of Hartwigsen, Goedecker and Hutter. ${ }^{62}$ Periodic boundary conditions at the $\Gamma$-point were used. A cut-off energy of 150 Hartrees was used with a $0.04 \mathrm{eV}$ Fermi smearing function for the electron temperature to aid self-consistent convergence. Geometries of all structures were fully optimized using a conjugate gradient algorithm with no constraints of symmetry until the maximum atomic position change in a given iteration dropped below $1 \times$ $10^{-7} \mathrm{eV} \AA^{-1}$. All calculations were done using a spin-averaged approach. Since the number of electrons of $\mathrm{Br}_{3}$ molecule is odd, we checked the effect of spin polarization on the total energy and vibration frequencies of $\mathrm{Br}_{3}$ over graphene (see ESI $\dagger$ ). Our results showed that accounting of spin has negligible effect on the vibration properties.

Atomic charge states were calculated using Mulliken population analysis. Binding energies are defined as follows: $E_{\mathrm{b}}=$ $E_{\text {tot }}-E_{\mathrm{h}}-N E_{\mathrm{Br}_{2}} / 2$, where $E_{\text {tot }}$ is the total energy of graphene (fluorinated graphene) with bromine, $E_{\mathrm{h}}$ is the energy of free layer, $E_{\mathrm{Br}_{2}}$ is the energy of isolated $\mathrm{Br}_{2}$, and $N$ is the number of bromine atoms. Vibrational frequencies were calculated by determining the energy and forces for 0.2 a.u. displacements of the bromine atoms. The second derivatives of the energy with respect to the positions of atoms $i$ and $j, \mathrm{~d}^{2} E / \mathrm{d} R_{i} \mathrm{~d} R_{j}$, were then obtained by a finite difference formulation of the derivative using the calculated forces. If all second derivatives $\mathrm{d}^{2} E$ are evaluated then the dynamical matrix can be found directly as $E_{i j} /\left(M_{i} M_{j}\right)^{0.5}$ where $M_{i}$ is the mass of the $i_{\text {th }}$ atom. This approach is discussed in ref. 63, where it was successfully used to identify stretching frequencies of bromine- and iodine-containing small molecules. Diffusion barriers were calculated using the climbing nudged elastic band (NEB) method with 10 or 12 images between the initial and final structures.

\section{Interaction between bromine species and graphene (fluorinated graphene)}

As shown in Table 1, adsorption of bromine species on graphene and fluorinated graphene is energetically favorable due to significant charge transfer. This is most obvious for $\mathrm{Br}_{3}$ which accepts about $0.8 e$ from graphene and $0.6 e$ from fluorinated graphene, stabilizing the $\mathrm{Br}_{3}$ anion. We note that the bromine does not form covalent bonds with the carbon.

The binding energy of $\mathrm{Br}_{2}$ with partially fluorinated graphene is $0.07 \mathrm{eV}$ higher than with pristine graphene (Table 1). NEB calculations show that migration of $\mathrm{Br}_{2}$ from the centre of a non-fluorinated region towards the fluorine chain (Fig. 2d) is energetically favorable with an enthalpy change of $c a .-0.15 \mathrm{eV}$ and an activation barrier of only ca. $0.04 \mathrm{eV}$ (Fig. 2e). When $\mathrm{Br}_{2}$ is placed above the fluorine chain, relaxation of this structure results in a shift of the molecule to adjacent non-fluorinated region. Therefore, when $\mathrm{Br}_{2}$ adsorbs on a graphene nanoregion present in a low-fluorinated layer, it should readily migrate to the CF interface.

\section{Normal vibration modes of adsorbed bromine species}

We next discuss the vibrational properties of free bromine species and those adsorbed on graphene and fluorinated graphene (Table 1). For an isolated $\mathrm{Br}_{2}$ molecule, the calculated

Table 1 Calculated geometry parameters ( $\mathrm{Br}-\mathrm{Br}$ bond length $h_{\mathrm{Br}-\mathrm{Br}}$, the shortest $\mathrm{Br}-\mathrm{C}$ distance $h_{\mathrm{C}-\mathrm{Br}}$ ), electronic structure (binding energy $E_{\mathrm{b}}$ per bromine atom, charge transfer $\left.Q_{\mathrm{Br}_{n}}\right)$ and stretching frequencies of free bromine species and those adsorbed on $\mathrm{graphene}\left(\mathrm{Br}_{2} / \mathrm{G}, \mathrm{Br}_{3} / \mathrm{G}, \mathrm{Br}_{3}-\mathrm{Br}_{3} / \mathrm{G}\right)$ and fluorinated graphene $\left(\mathrm{Br}_{2} / \mathrm{FG}, \mathrm{Br}_{3} / \mathrm{FG}, \mathrm{Br}_{3}-\mathrm{Br}_{3} / \mathrm{FG}\right.$ ). Frequencies $\nu_{3}^{a}$ (shown in italics) correspond to Raman-inactive vibrations for linear $\mathrm{Br}_{3}$ structure. Values for isolated $\mathrm{Br}_{2}, \mathrm{Br}_{3}$, and $\mathrm{Br}_{3}{ }^{-}$are listed for reference. The last column shows the Raman bands in the spectra of $\mathrm{G}-\mathrm{Br}$ and $\mathrm{C}_{2} \mathrm{~F}_{x}-\mathrm{Br}$ samples from Fig. 1. The experimental frequencies are listed alongside the species we are assigning them to

\begin{tabular}{|c|c|c|c|c|c|c|}
\hline & $h_{\mathrm{Br}-\mathrm{Br}}(\AA)$ & $h_{\mathrm{Br}-\mathrm{C}}(\AA)$ & $E_{\mathrm{b}} / \mathrm{Br}(\mathrm{eV})$ & $Q_{\mathrm{Br}_{n}}(e)$ & $\nu\left(\mathrm{cm}^{-1}\right)$ & expt. $\left(\mathrm{cm}^{-1}\right)$ \\
\hline $\mathrm{Br}_{2}(Q=-1 e)$ & 2.3 & & & & $151.9\left(\nu_{2}^{\mathrm{s}}\right)$ & Peak II: 206 \\
\hline $\mathrm{Br}_{3}^{-}(Q=-1 e)$ & 2.5 & & & & $\begin{array}{l}164.4\left(\nu_{3}{ }^{\mathrm{s}}\right) \\
215.0\left(\nu_{3}{ }^{\mathrm{a}}\right)\end{array}$ & $\begin{array}{l}\text { Peak V: } 410 \\
\text { Peak VI: } 473\end{array}$ \\
\hline $\mathrm{Br}_{2} / \mathrm{G}$ & 2.3 & 3.6 & -0.15 & -0.16 & $233.9\left(\nu_{2}^{\mathrm{s}}\right)-$ peak III & \\
\hline $\mathrm{Br}_{3}-\mathrm{Br}_{3} / \mathrm{G}$ & $\begin{array}{l}2.5\left(\mathrm{Br}_{3}\right) \\
3.0\left(\mathrm{Br}_{3}-\mathrm{Br}_{3}\right)\end{array}$ & 3.3 & -0.39 & -1.28 & $\begin{array}{l}158.7\left(\nu_{3}{ }^{\mathrm{s}}-\nu_{3}{ }^{\mathrm{s}}\right)-\text { peak I } \\
223.1\left(\nu_{3}{ }^{\mathrm{a}}-\nu_{3}{ }^{\mathrm{a}}\right)-\text { peak III }\end{array}$ & \\
\hline $\mathrm{Br}_{2} / \mathrm{FG}$ & 2.3 & 3.4 & -0.22 & -0.12 & 308.2 -peak IV & \\
\hline $\mathrm{Br}_{3} / \mathrm{FG}$ & 2.5 & 3.2 & -0.44 & -0.59 & $\begin{array}{l}176.0\left(\nu_{3}^{\mathrm{s}}\right)-\text { peak I } \\
229.6\left(\nu_{3}^{\mathrm{a}}\right)-\text { peak III }\end{array}$ & \\
\hline $\mathrm{Br}_{3}-\mathrm{Br}_{3} / \mathrm{FG}$ & $\begin{array}{l}2.5\left(\mathrm{Br}_{3}\right) \\
2.9\left(\mathrm{Br}_{3}-\mathrm{Br}_{3}\right)\end{array}$ & 3.2 & -0.36 & -1.13 & $\begin{array}{l}163.3\left(\nu_{3}^{\mathrm{s}}-\nu_{3}{ }^{\mathrm{s}}\right)-\text { peak I } \\
231.9\left(\nu_{3}{ }^{\mathrm{a}}-\nu_{3}{ }^{\mathrm{a}}\right)-\text { peak III }\end{array}$ & \\
\hline
\end{tabular}


symmetric $\mathrm{Br}-\mathrm{Br}$ stretching frequency $\nu_{2}^{\mathrm{s}}$ is $326.2 \mathrm{~cm}^{-1}$ in almost coincidence with the experimental value $\left(323 \mathrm{~cm}^{-1}\right) .{ }^{48}$ This frequency is downshifted to $233.9 \mathrm{~cm}^{-1}$ due to interaction of $\mathrm{Br}_{2}$ with graphene (Fig. 2a) that perfectly matches the position of Raman peak III. Previous theoretical investigations of brominated graphene and graphite showed significant overestimation of this frequency (up to $260-290 \mathrm{~cm}^{-1}$ ), ${ }^{14,20,30,55}$ and to match experiment, an additional negative charge ( $c a .0 .5 e$ ) was assigned to $\mathrm{Br}_{2} \cdot{ }^{14}$ This overestimation is due to use of periodic cells that are too small. We found that this mode converges rapidly to the experimental value with increasing cell size (Table S2 and Fig. S2 in ESI $\dagger$ ). The actual charge transfer from graphene to $\mathrm{Br}_{2}$ is much weaker $\left(Q_{\mathrm{Br}_{2}}=-0.16 e\right)$.

$\mathrm{A} \mathrm{Br}_{2}$ molecule has only a single stretching motion, while polyatomic bromine species exhibit more complex vibrations. Isolated $\mathrm{Br}_{3}$ and $\mathrm{Br}_{3}{ }^{-}$have a linear centrosymmetric structure with deformation vibration $\nu_{3}{ }^{\mathrm{b}}$ (58.2 and $\left.83.4 \mathrm{~cm}^{-1}\right)$, symmetric stretching vibration $\nu_{3}^{\mathrm{s}}$ (189.6 and $164.0 \mathrm{~cm}^{-1}$ ), and asymmetric stretching vibration $\nu_{3}{ }^{a}\left(243.7\right.$ and $\left.215.0 \mathrm{~cm}^{-1}\right)$ in agreement with previous experimental and theoretical results. ${ }^{64}$ We will not consider further the $\nu_{3}{ }^{\mathrm{b}}$ mode. The general expectation is a downshift of the stretching modes when $\mathrm{Br}_{3}$ interacts with graphene or partially fluorinated graphene layer. Indeed, for $\mathrm{Br}_{3}$ over graphene (fluorinated graphene), our calculated modes $\nu_{3}{ }^{\mathrm{a}}$ and $\nu_{3}^{\mathrm{s}}$ have frequencies 220.3 and $164.3 \mathrm{~cm}^{-1}$ (229.6 and $176.0 \mathrm{~cm}^{-1}$, Table 1 and Fig. 2b). According to the selection rules, the mode $\nu_{3}{ }^{\mathrm{s}}$ is only Raman-active for linear $\mathrm{Br}_{3}$. However, the host matrix may distort symmetry of $\mathrm{Br}_{3}{ }^{65}$ and in this case the Raman spectrum will have additional, low-intensity peak $\nu_{3}{ }^{\mathrm{a}}$.

Another possible mechanism to overcome the symmetry restriction in Raman is the formation of polybromide chains. When two coaxial $\mathrm{Br}_{3}$ molecules are placed in line, they can perform asymmetric stretching simultaneously, as mirror images of each other. The chain-like $\mathrm{Br}_{3}-\mathrm{Br}_{3}$ species has two Raman-active stretching modes $\nu_{3}{ }^{\mathrm{s}}-\nu_{3}{ }^{\mathrm{s}}$ and $\nu_{3}{ }^{\mathrm{a}}-\nu_{3}{ }^{\mathrm{a}}$ (Fig. 2c, bending modes with frequencies below $100 \mathrm{~cm}^{-1}$ are missed). For $\mathrm{Br}_{3}-\mathrm{Br}_{3}$ over graphene, the first mode $\nu_{3}{ }^{\mathrm{s}}-\nu_{3}{ }^{\mathrm{s}}$ at $158.7 \mathrm{~cm}^{-1}$ corresponds to the simultaneous symmetric stretching of both $\mathrm{Br}_{3}$ constituents and coincides with the position of the experimental peak I. The mirror asymmetric stretching of $\mathrm{Br}_{3}$ molecules yields the mode $\nu_{3}{ }^{\mathrm{a}}-\nu_{3}{ }^{\mathrm{a}}$ at $223.1 \mathrm{~cm}^{-1}$, which is close to the Raman peak III. Several $\mathrm{Br}_{3}-\mathrm{Br}_{3}$ configurations on fluorinated graphene were examined (Fig. S3 and Table S3 in ESI $\dagger$ ), and we identified other metastable structures. Their binding energies are less by $0.01-0.02 \mathrm{eV}$ than that of the lowest energy configuration (Fig. 2e). These structures show significant variation in frequency of both vibration modes $\nu_{3}{ }^{\mathrm{s}}-\nu_{3}{ }^{\mathrm{s}}=$ 159.6-181.9 $\mathrm{cm}^{-1}$ and $\nu_{3}{ }^{\mathrm{a}}-\nu_{3}{ }^{\mathrm{a}}=225.2-231.9 \mathrm{~cm}^{-1}$, and thus could lead to some broadening of the related peaks.

\section{Polycondensation of bromine molecules}

Theoretical studies on the formation of polybromine chains inside small-diameter $\mathrm{CNTs}^{32}$ and above graphene layers ${ }^{33}$ have shown contradictory results. In particular, it was found that anions from an odd number of atoms, such as $\mathrm{Br}_{3}{ }^{-}$and
$\mathrm{Br}_{5}{ }^{-}$could be formed almost without barrier due to charge transfer from the nanotube to the encapsulated species. On the other hand, exothermic formation of polybromine chains over graphene was suggested to have a significant activation barrier for the reaction $2 \mathrm{Br}_{2} \rightarrow \mathrm{Br}_{4} \cdot{ }^{33}$

To try and resolve this contradiction we calculated the path for the reaction $3 \mathrm{Br}_{2} \rightarrow \mathrm{Br}_{3}-\mathrm{Br}_{3}$ over fluorinated graphene (Fig. 3). The initial NEB configuration is the optimized geometries of three bromine molecules evenly spaced over pristine graphene region located between CF chains. These molecules are denoted $i$ and marked by red dashed ovals in Fig. $3 \mathrm{a}$ and $\mathrm{b}$.

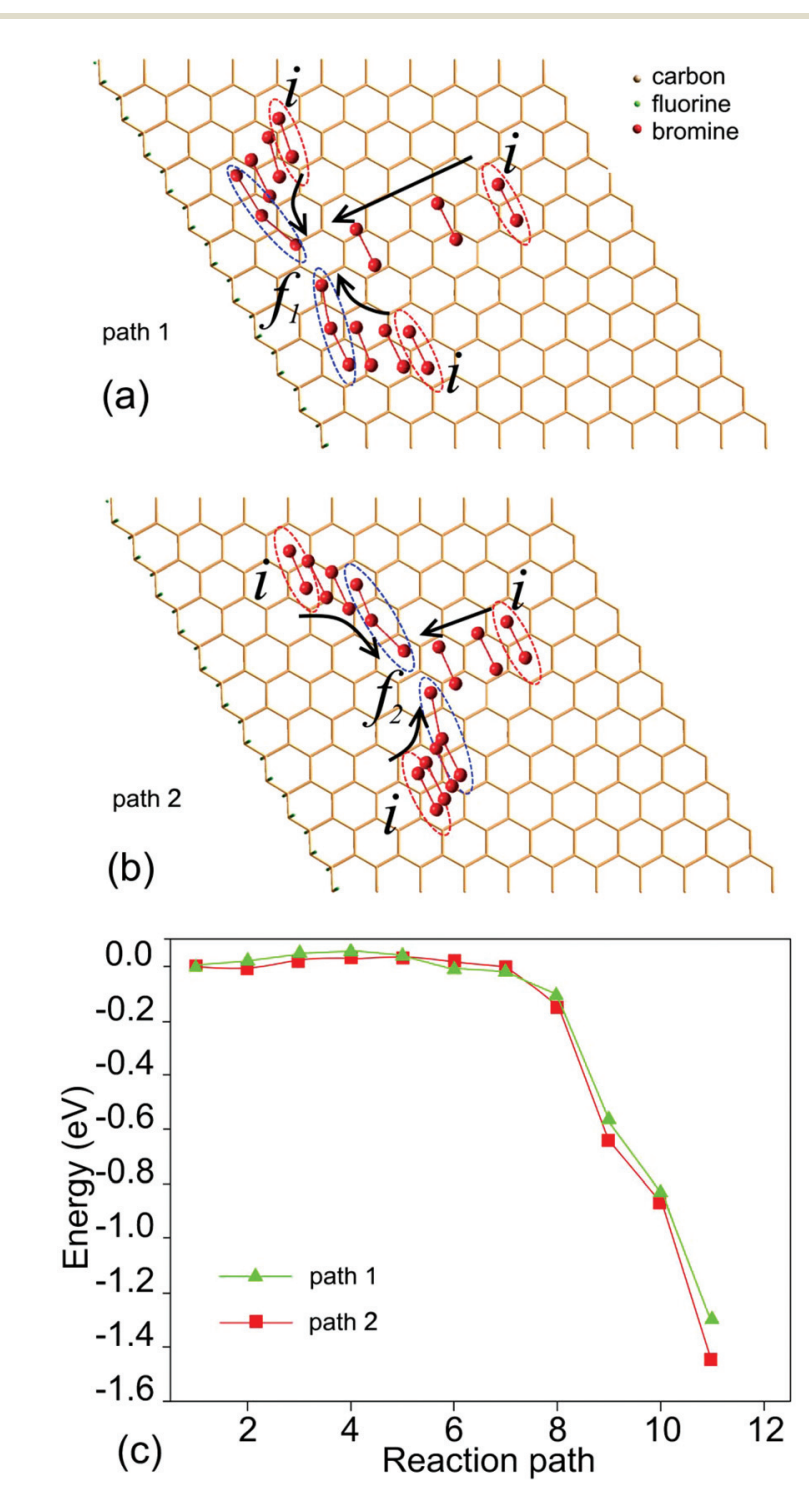

Fig. 3 NEB simulation of reaction paths of $3 \mathrm{Br}_{2} \rightarrow \mathrm{Br}_{3}-\mathrm{Br}_{3}$, when final $\mathrm{Br}_{3}-\mathrm{Br}_{3}$ is located near to (a) or far from (b) the fluorine boundary. The initial positions of three $\mathrm{Br}_{2}$ marked by red dashed ovals (denoted $i$ ), the final positions of $\mathrm{Br}_{3}-\mathrm{Br}_{3}$ marked by blue dashed ovals (denoted $f_{1}$ and $f_{2}$ ). Arrows indicate the reaction paths, $i \rightarrow f_{1}$ in (a) and $i \rightarrow f_{2}$ in (b). The $\mathrm{Br}-\mathrm{Br}$ distance increases from $2.3 \AA$ in $\mathrm{Br}_{2}$ to $2.5 \AA$ in $\mathrm{Br}_{3}$, the distance between $\mathrm{Br}_{3}$ in the $\mathrm{Br}_{3}-\mathrm{Br}_{3}$ chain is $\sim 3.0 \AA$. Diffusion barriers calculated for two reaction paths 1 and 2 (c). 
We explored two final structures of the $\mathrm{Br}_{3}-\mathrm{Br}_{3}$ chain located near to or far from the fluorine chain (denoted $f_{1}$ and $f_{2}$ respectively and marked by blue dashed ovals in Fig. 3a and b). The potential surfaces of transformation of three $\mathrm{Br}_{2}$ into $\mathrm{Br}_{3}-\mathrm{Br}_{3}$ indicate that these reactions are exothermic with a negligible energetic barrier (about 0.04 and $0.05 \mathrm{eV}$ for the reactions $i \rightarrow f_{1}$ and $i \rightarrow f_{2}$, respectively). Therefore, the formation of $\mathrm{Br}_{3}-\mathrm{Br}_{3}$ chains over nanoscale graphene region will occur spontaneously in agreement with polymerization of bromine molecules encapsulated inside nanotubes. ${ }^{32}$

\section{Discussion}

G-Br and $\mathrm{C}_{2} \mathrm{~F}_{x}$ - $\mathrm{Br}$ samples $(x=0.07,0.24,0.47)$ have almost identical Raman spectra. The most intense peak III at $c a$. $237 \mathrm{~cm}^{-1}$ lies close to three calculated modes, namely the symmetric stretching of intercalated $\mathrm{Br}_{2}$ and $\mathrm{Br}_{3}-\mathrm{Br}_{3}$ species and the asymmetric stretching of $\mathrm{Br}_{3}$. In practise it is likely to be a combination of the three, which can explain also why it is relatively broad. The symmetrical stretching of $\mathrm{Br}_{3}$ in $\mathrm{Br}_{3}-\mathrm{Br}_{3}$ species supplies the peak I at $157 \mathrm{~cm}^{-1}$.

Formation of $\mathrm{Br}_{3}$-based chains in partially fluorinated graphite was found to be spontaneous. The key role in this process belongs to interaction of adsorbed bromine molecules with small pristine graphene regions framed with $\mathrm{C}-\mathrm{F}$ borders. Moving across such areas, bromine molecules can meet each other. As the result, bounded $\mathrm{Br}_{3}-\mathrm{Br}_{3}$ chains are formed. Moreover, according to the study of bromine species encapsulated in CNTs, ${ }^{32} \mathrm{Br}_{5}$ anions could be formed from $\mathrm{Br}_{3}$ and $\mathrm{Br}_{2}$, and they are observed as the Raman resonances located around $206 \mathrm{~cm}^{-1}$ (peak II). ${ }^{33}$ The weak intensity band at $c a$. $323 \mathrm{~cm}^{-1}$ (peak IV) could be attributed to intercalated bromine molecules sitting above fluorinated regions.

A comparison of the Raman spectra in Fig. 1 suggests that bromine behaves differently in highly fluorinated graphite, and for $\mathrm{C}_{2} \mathrm{~F}_{0.94}-\mathrm{Br}$ the spectrum resembles that of liquid bromine. This indicates the intercalate contains bromine molecules separated by the van der Waals distance. The high fluorination degree in $\mathrm{C}_{2} \mathrm{~F}_{0.94}-\mathrm{Br}$ means that every second carbon atom binds with fluorine, and the extended pristine graphene regions are absent. In this case the bromine molecules are located between CF chains of fluorinated graphite layers above non-fluorinated carbon chains, and interact only weakly with the host matrix.

\section{Remarks about bromination of carbons}

We used a gaseous mixture of $\mathrm{BrF}_{3}$ and $\mathrm{Br}_{2}$ as the fluorinating agent because of its ability to fluorinate graphite at room temperature. Simultaneously the synthesis procedure results in intercalation of bromine and bromine fluoride species. In order to remove bromine fluorides and enrich the samples with bromine, we held them in $\mathrm{Br}_{2}$ vapour. However, even when the last step is omitted, the Raman spectra of low-fluorinated matrices exhibit the peaks I-VI (see Fig. S4 $\dagger$ ). The Raman spectrum of $\mathrm{C}_{2} \mathrm{~F}_{0.94}$ sample without additional bromination does not have any features related with the intercalated bromine species. This confirms a weak interaction between $\mathrm{Br}_{2}$ and highly-fluorinated graphite matrix.

Bundles of CNTs and fluorinated CNTs (F-CNTs) can also be intercalated with bromine. Commonly bromine gets into inter-tubular spaces in the bundles. ${ }^{4,14}$ The donor-acceptor interaction between CNTs and bromine and spatial confinement of intercalated molecules inside 1D-channels between tubes should drive the bromine polycondensation in CNTs and F-CNTs similarly to that in brominated graphite and lowfluorinated $\mathrm{C}_{2} \mathrm{~F}_{\mathrm{x}}$. To confirm this assumption, we synthesized brominated DWCNTs (denoted as DWCNT-Br) and fluorinated DWCNTs (denoted as F-DWCNT-Br) using a similar procedure to that described above for graphite. Details of the synthesis is given in our previous studies. ${ }^{4-6,66,67}$ Briefly, DWCNT powder was put in a perforated Teflon flask and this flask was placed on a stand in a larger Teflon flask containing liquid bromine at the bottom and held at room temperature for 4 days. The product was dried by a flow of $\mathrm{N}_{2}$ to remove weakly bonded $\mathrm{Br}_{2}$. The sample is referred to as Br-DWCNT. Fluorination of DWCNTs was carried out using solution of $\mathrm{BrF}_{3}$ (3 wt\%) in $\mathrm{Br}_{2}$ at room temperature for 7 days. Thereafter, the product (F-DWCNT-Br) was purged by a flow of $\mathrm{N}_{2}$ to remove weakly adsorbed $\mathrm{Br}_{2}$. Based on X-ray photoelectron spectroscopy analysis, performed at the Berliner Elektronenspeicher ring für Synchrotronstrahlung (BESSY II) using radiation from the Russian-German beamline at a monochromatic radiation of $830 \mathrm{eV}$, a surface stoichiometry of DWCNT-Br and

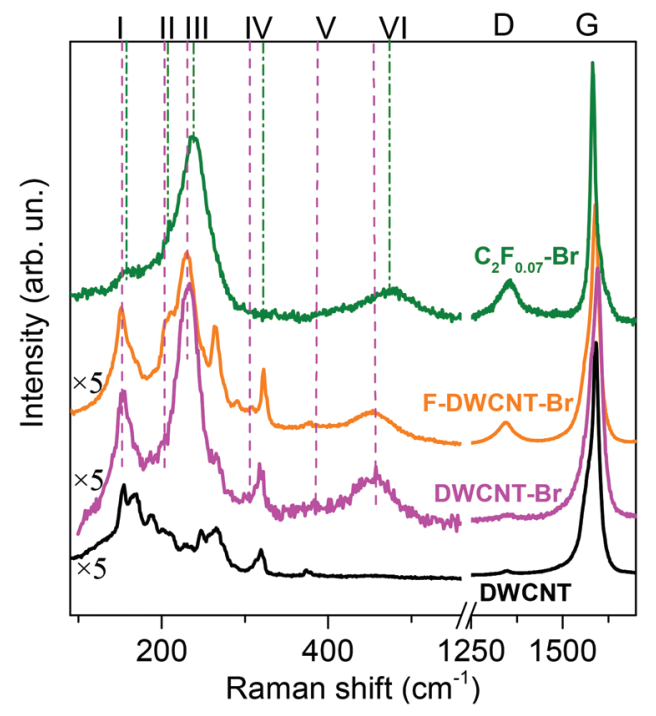

Fig. 4 Raman spectra taken at $514 \mathrm{~nm}$ for pristine DWCNTs, brominated DWCNTs (DWCNT-Br), brominated fluorinated DWCNTs (F-DWCNT-Br), and fluorinated graphite intercalation compound $\mathrm{C}_{2} \mathrm{~F}_{0.07}-\mathrm{Br}$. Positions of peaks I-VI in the spectra of DWCNT-Br and $\mathrm{C}_{2} \mathrm{~F}_{0.07}-\mathrm{Br}$ samples are shown by dashed and dot-dashed lines, respectively. 
F-DWCNT-Br samples is $\mathrm{C}_{2} \cdot \mathrm{Br}_{0.13}$ and $\mathrm{C}_{2} \mathrm{~F}_{0.15} \cdot \mathrm{Br}_{0.09}$, respectively. Low fluorine content in the latter sample supposes presence of extended non-fluorinated segments on the DWCNT surface.

Fig. 4 shows the Raman spectra of DWCNT-Br and F-DWCNT-Br samples in comparison with the spectra of pristine DWCNTs and bromine-intercalated fluorinated graphite $\mathrm{C}_{2} \mathrm{~F}_{0.07}-\mathrm{Br}$. Despite the $\mathrm{Br}-\mathrm{Br}$ vibrations overlaying the radial breathing modes (RBMs) of the outer and inner DWCNT shells, the features previously denoted as I-VI are clearly visible. We suppose that they arise from the characteristic vibrations of different bromine species intercalated in the DWCNT ropes, i.e. $\mathrm{Br}_{2}$ is also condensed into $\mathrm{Br}_{3}$-based chains if they are located in close vicinity between the nanotubes. Therefore, one can conclude that interaction of bromine with graphite and CNTs takes place in a similar manner if extended non-functionalized $\mathrm{sp}^{2}$-regions are preserved.

Bromination and fluorination increase the intertube distance causing a partial debundling of the nanotubes. As a result, bromine is less influenced by interaction with the nanotube surface, softening the Raman bands in comparison with that in $\mathrm{C}_{2} \mathrm{~F}_{0.07}-\mathrm{Br}$.

\section{Conclusion}

In summary, by closely coupling experimental and DFT calculated Raman frequencies on a quantitative level never previously used in the literature, we have explored bromination of different $\mathrm{sp}^{2}$-hybridized carbon materials (graphite, partially fluorinated graphite, DWCNTs, and fluorinated DWCNTs). Our results show that depending on the fluorination level two types of intercalated bromine species occur. The first is liquidlike layers of bromine $\left(\mathrm{Br}_{2}\right)$, confined between highly fluorinated graphitic layers with approximately $\mathrm{C}_{2} \mathrm{~F}$. In this case, the intercalated species shows a single Br-related Raman peak at ca. $311 \mathrm{~cm}^{-1}$. In contrast, the Raman spectra of brominated pristine and low-fluorinated graphites and DWCNTs are rich, indicating a more complex organisation of the guest molecules. When the fluorination degree is low enough, $\mathrm{C}_{2} \mathrm{~F}_{x}$ layers contain extended bare graphene nanoregions, which attract the intercalated bromine. This interaction is accompanied by significant charge transfer from the substrate to $\mathrm{Br}_{2}$ and can be detected as the Raman band at $c a .237 \mathrm{~cm}^{-1}$. In addition, polybromide species constructed from $\mathrm{Br}_{3}$ can be formed spontaneously over such nanoregions, due to the negligible calculated activation barrier and large enthalpy value $(-1.4 \mathrm{eV})$. Formation of polybromides, such as weakly bound chains of $\mathrm{Br}_{3}$, arises from free diffusion of the adsorbed $\mathrm{Br}_{2}$ anions over non-fluorinated regions of the graphene sheet toward the fluorinated border. This condensed species over $\mathrm{sp}^{2}$-hybridized carbons is responsible for the additional Raman peaks at 157 and $206 \mathrm{~cm}^{-1}$ as well as contributing to the feature at $237 \mathrm{~cm}^{-1}$. We propose that this polycondensation mechanism is common for all $\mathrm{sp}^{2}$-hybridized carbon materials containing extended graphene nanoregions.

\section{Conflicts of interest}

There are no conflicts to declare.

\section{Acknowledgements}

The study of graphites was funded by the Russian Foundation for Basic Research (RFBR, grant no. 18-29-19073) and EU IRSES Project 612577 "NanoCF”. The study of DWCNTs was supported by the RFBR (grant no. 16-53-150003) and the PRC CNRS/RFBR (grant no. 1023). We also thanks the Academy of Finland (grant no 318345) for support. We are grateful to Prof. B. A. Kolesov for the Raman data and fruitful discussion. Some of the calculations were performed at the CCIPL (Centre de Calculs Intensif Pays de la Loire).

\section{References}

1 E. Widenkvist, D. W. Boukhvalov, S. Rubino, S. Akhtar, J. Lu, R. A. Quinlan, M. I. Katsnelson, K. Leifer, H. Grennberg and U. Jansson, J. Phys. D: Appl. Phys., 2009, 42, 112003.

2 L. G. Bulusheva, V. A. Tur, E. O. Fedorovskaya, I. P. Asanov, D. Pontiroli, M. Riccò and A. V. Okotrub, Carbon, 2014, 78, 137-146.

3 D. D. Chronopoulos, A. Bakandritsos, M. Pykal, R. Zbořil and M. Otyepka, Appl. Mater. Today, 2017, 9, 60-70.

4 L. G. Bulusheva, A. V. Okotrub, E. Flahaut, I. P. Asanov, P. N. Gevko, V. O. Koroteev, Y. V. Fedoseeva, A. Yaya and C. P. Ewels, Chem. Mater., 2012, 24, 2708-2715.

5 L. G. Bulusheva, Yu. V. Fedoseeva, A. V. Okotrub, E. Flahaut, I. P. Asanov, V. O. Koroteev, A. Yaya, C. P. Ewels, A. L. Chuvilin, A. Felten, G. Van Lier and D. V. Vyalikh, Chem. Mater., 2010, 22, 4197-4203.

6 L. G. Bulusheva, Y. V. Fedoseeva, E. Flahaut, J. Rio, C. P. Ewels, V. O. Koroteev, G. Van Lier, D. V. Vyalikh and A. V. Okotrub, Beilstein J. Nanotechnol., 2017, 8, 1688-1698.

7 L. G. Bulusheva, A. V. Okotrub and N. F. Yudanov, Phys. Low-Dimens. Struct., 2002, 7-8, 1-14.

8 A. V. Okotrub, N. F. Yudanov, I. P. Asanov, D. V. Vyalikh and L. G. Bulusheva, ACS Nano, 2013, 7, 65-74.

9 A. Vyalikh, L. G. Bulusheva, G. N. Chekhova, D. V. Pinakov, A. V. Okotrub and U. Scheler, J. Phys. Chem. C, 2013, 117, 7940-7948.

10 T. L. Makarova, A. L. Shelankov, A. I. Shames, A. A. Zyrianova, A. A. Komlev, G. N. Chekhova, D. V. Pinakov, L. G. Bulusheva, A. V. Okotrub and E. Lähderanta, Sci. Rep., 2017, 7, 16544.

11 F. Karlický, K. K. R. Datta, M. Otyepka and R. Zbořil, ACS Nano, 2013, 7, 6434-6464.

12 I. P. Asanov, A. V. Okotrub, A. V. Gusel'nikov, I. V. Yushina, D. V. Vyalikh and L. G. Bulusheva, Carbon, 2015, 82, 446458. 
13 L. G. Bulusheva and A. V. Okotrub, in Electronic structure of fluorinated graphene, New Fluorinated Carbons: Fundamentals and Applications, ed. O. V. Boltalina and T. Nakajima, Elsevier, Amsterdam, 2017, 177-213.

14 A. L. Aguiar, E. B. Barros, V. P. Sousa Filho, H. Terrones, V. Meunier, D. Machon, Y. A. Kim, H. Muramatsu, M. Endo, F. Baudelet, A. San-Miguel and A. G. Souza Filho, J. Phys. Chem. C, 2017, 121, 10609-10619.

15 S. Żarska, D. Kulawik, J. Drabowicz and W. Ciesielski, Fullerenes, Nanotubes, Carbon Nanostruct., 2017, 25, 563569.

16 H. Au, N. Rubio and M. S. P. Shaffer, Chem. Sci., 2018, 9, 209-217.

17 T. Sasa, Y. Takahashi and T. Mukaibo, Bull. Chem. Soc. Jpn., 1970, 43, 34-38.

18 S. Tongay, J. Hwang, D. B. Tanner, H. K. Pal, D. Maslov and A. F. Hebard, Phys. Rev. B: Condens. Matter Mater. Phys., 2010, 81, 115428.

19 N. Jung, A. C. Crowther, K. Kim, P. Kim and L. Brus, ACS Nano, 2010, 4, 7005-7013.

20 A. E. Mansour, S. Dey, A. Amassian and M. H. Tanielian, ACS Appl. Mater. Interfaces, 2015, 7, 17692-17699.

21 V. O. Koroteev, W. Münchgesang, Yu. V. Shubin, Yu. N. Palyanov, P. E. Plyusnin, D. A. Smirnov, K. A. Kovalenko, M. Bobnar, R. Gumeniuk, E. Brendler, D. C. Meyer, L. G. Bulusheva, A. V. Okotrub and A. Vyalikh, Carbon, 2017, 124, 161-169.

22 D. Hines, M. H. Rümmeli, D. Adebimpe and D. L. Akins, Chem. Commun., 2014, 50, 11568-11571.

23 Z. Chen, X. Du, M.-H. Du, C. D. Rancken, H.-P. Cheng and A. G. Rinzler, Nano Lett., 2003, 3, 1245-1249.

24 W. T. Eeles and J. A. Turnbull, Proc. R. Soc. London, Ser. A, 1965, 283, 179-193.

25 T. Sasa, Y. Takahashi and T. Mukaibo, Carbon, 1971, 9, 407-416.

26 P. C. Eklund, N. Kambe, G. Dresselhaus and M. S. Dresselhaus, Phys. Rev. B: Condens. Matter Mater. Phys., 1978, 18, 7069.

27 D. Ghosh and D. D. L. Chung, Mater. Res. Bull., 1983, 18, 1179-1187.

28 Ch. Simon, F. Batallan, I. Rośenman, H. Lauter and G. Furdin, Phys. Rev. B: Condens. Matter Mater. Phys., 1983, 27, 5088.

29 A. Erbil, A. R. Kortan, R. J. Birgeneau and M. S. Dresselhaus, Phys. Rev. B: Condens. Matter Mater. Phys., 1983, 28, 6329.

30 A. Erbil, G. Dresselhaus and M. S. Dresselhaus, Phys. Rev. B: Condens. Matter Mater. Phys., 1982, 25, 5451.

31 P. Barpanda, G. Fanchini and G. G. Amatucci, Carbon, 2011, 49, 2538-2548.

32 D. Sung, N. Park, W. Park and S. Hong, Appl. Phys. Lett., 2007, 90, 093502.

33 A. Yaya, C. P. Ewels, J. K. Efavi, B. Agyei-Tuffour, K. KanDapaah, B. Onwona-Agyeman, E. K. K. Abavare, A. Hassanali and P. R. Briddon, Cogent Eng., 2016, 3, 1261509.
34 B. Liu, Q. Cui, M. Yu, G. Zou, J. Carlsten, T. Wagberg and B. J. Sundqvist, J. Phys.: Condens. Matter, 2002, 14, 11255.

35 J. Strauch, B. Anis and C. A. Kuntscher, Phys. Status Solidi $B, 2014,251,2378-2383$.

36 A. A. Tonkikh, D. V. Rybkovskiy, A. S. Orekhov, A. I. Chernov, A. A. Khomich, C. P. Ewels, E. I. Kauppinen, S. B. Rochal, A. L. Chuvilin and E. D. Obraztsova, Carbon, 2016, 109, 87-97.

37 J. Cambedouzou, J.-L. Sauvajol, A. Rahmani, E. Flahaut, A. Peigney and C. Laurent, Phys. Rev. B: Condens. Matter Mater. Phys., 2004, 69, 235422.

38 D. V. Rybkovskiy, A. Impellizzeri, E. D. Obraztsova and C. P. Ewels, Carbon, 2018, 142, 123-130.

39 Z. Liu, M. Yao, Y. Yuan, S. Chen, R. Liu, S. Lu, B. Zou, T. Cui and B. Liu, J. Raman Spectrosc., 2015, 46, 413-417.

40 G. A. Saunders, A. R. Ubbelohde and D. A. Young, Proc. R. Soc. London, Ser. A, 1963, 271, 499-511.

41 G. N. Chekhova, E. A. Ukraintseva, I. M. Ivanov, N. F. Yudanov, Yu. V. Shubin, V. A. Logvinenko, D. V. Pinakov, V. P. Fadeeva and N. I. Alferova, Russ. J. Inorg. Chem., 2005, 50, 1055-1061.

42 D. V. Pinakov and V. A. Logvinenko, J. Therm. Anal. Calorim., 2006, 86, 173-178.

43 V. P. Fadeeva, V. D. Tikhova and O. N. Nikulicheva, J. Anal. Chem., 2008, 63, 1094-1106.

44 V. P. Fadeeva and I. M. Moryakina, Moscow, 1989, dep. in VINITI № 2579-889.

45 I. P. Asanov, L. G. Bulusheva, M. Dubois, N. F. Yudanov, A. V. Alexeev, T. L. Makarova and A. V. Okotrub, Carbon, 2013, 59, 518-529.

46 A. Cholach, I. Asanov, A. Bryliakova, T. Asanova, D. Pinakov, A. Okotrub and M.-G. Kim, AIP Adv., 2018, 8, 085319.

47 J. E. Cahill and G. E. Leroi, J. Chem. Phys., 1969, 51, 45144519.

48 G. Herzberg, Spectra of Diatomic Molecules, Van Nostrand, New York, 2nd edn, 1948, vol. 1, p. 368.

49 A. G. Souza Filho, M. Endo, H. Muramatsu, T. Hayashi, Y. A. Kim, E. B. Barros, N. Akuzawa, Ge. G. Samsonidze, R. Saito and M. S. Dresselhaus, Phys. Rev. B: Condens. Matter Mater. Phys., 2006, 73, 235413.

50 B. Wang, J. Wang and J. Zhu, ACS Nano, 2014, 8, 18621870.

51 P. Gong, Z. Wang, J. Wang, H. Wang, Z. Li, Z. Fan, Y. Hu, X. Han and S. Yang, J. Mater. Chem., 2012, 22, 1695016956.

52 R. R. Nair, M. Sepioni, I.-L. Tsai, O. Lehtinen, J. Keinonen, A. V. Krasheninnikov, T. Thomson, A. K. Geim and I. V. Grigorieva, Nat. Phys., 2012, 8, 199-202.

53 G. Van Lier, C. P. Ewels, F. Zuliani, A. De Vita and J.-C. Charlier, J. Phys. Chem. B, 2005, 109, 6153-6158.

54 D. W. Boukhvalov, Phys. Chem. Chem. Phys., 2016, 18, 13287-13293.

55 A. Yaya, C. P. Ewels, I. Suarez-Martinez, Ph. Wagner, S. Lefrant, A. Okotrub, L. Bulusheva and P. R. Briddon, 
Phys. Rev. B: Condens. Matter Mater. Phys., 2011, 83, 045411.

56 J.-C. Charlier, X. Gonze and J.-P. Michenaud, Europhys. Lett., 1994, 28, 403-408.

57 Y. S. Al-Hamdani, D. Alfè and A. Michaelides, J. Chem. Phys., 2017, 146, 094701.

58 R. Jones and P. Briddon, Semicond. Semimetals, 1998, 51, 287-349.

59 M. J. Rayson and P. R. Briddon, Comput. Phys. Commun., 2008, 178, 128-134.

60 M. J. Rayson and P. R. Briddon, Phys. Rev. B: Condens. Matter Mater. Phys., 2009, 80, 205104.

61 I. Suarez-Martinez, A. A. El-Barbary, G. Savini and M. I. Heggie, Phys. Rev. Lett., 2007, 98, 015501.
62 C. Hartwigsen, S. Goedecker and J. Hutter, Phys. Rev. B: Condens. Matter Mater. Phys., 1998, 58, 36413662 .

63 V. Guiot, I. Suarez-Martinez, Ph. Wagner, J. Goss, P. R. Briddon, A. W. Allaf and C. P. Ewels, Inorg. Chem., 2009, 48, 3660-3666.

64 P. Schuster, H. Mikosch and G. Bauer, J. Chem. Phys., 1998, 109, 1833-1844.

65 G. R. Burns and R. M. Renner, Spectrochim. Acta, Part A, 1991, 47, 991-999.

66 E. Flahaut, R. Bacsa, A. Peigney and C. Laurent, Chem. Commun., 2003, 1442-1443.

67 S. Osswald, E. Flahaut, H. Ye and Y. Gogotsi, Chem. Phys. Lett., 2005, 402, 422-427. 


\section{Supporting Information for}

\section{Bromine polycondensation in pristine and fluorinated graphitic carbons}

Olga V. Sedelnikova, ${ }^{* a, b}$ Christopher P. Ewels, ${ }^{* c}$ Dmitriy V. Pinakov, ${ }^{a}{ }^{a}$ Galina N. Chekhova, ${ }^{a}$ Emmanuel Flahaut, ${ }^{\mathrm{d}, \mathrm{e}}$ Alexander V. Okotrub ${ }^{\mathrm{a}, \mathrm{b}}$ and Lyubov G. Bulusheva ${ }^{\mathrm{a}, \mathrm{b}}$

${ }^{a}$ Nikolaev Institute of Inorganic Chemistry SB RAS, 3 Academician Lavrentiev Av., Novosibirsk 630090, Russian Federation.E-mail: o.sedelnikova@gmail.com

${ }^{b}$ Novosibirsk State University, 2 Pirogov Str., Novosibirsk 630090, Russian Federation

'Institut des Matériaux Jean Rouxel, CNRS-Université de Nantes, UMR6502, 2 Rue de la Houssinière, BP32229, 44322 Nantes cedex 3, France

'Université de Toulouse; UPS, INP; Institut Carnot Cirimat; 118, route de Narbonne, F-31062 Toulouse cedex 9, France

${ }^{e}$ CNRS, Institut Carnot Cirimat, F-31062 Toulouse, France

\section{Corresponding Authors}

* O.V.S. : e-mail o.sedelnikova@gmail.com.; C.P.E.: e-mail chris.ewels@cnrs-imn.fr. 

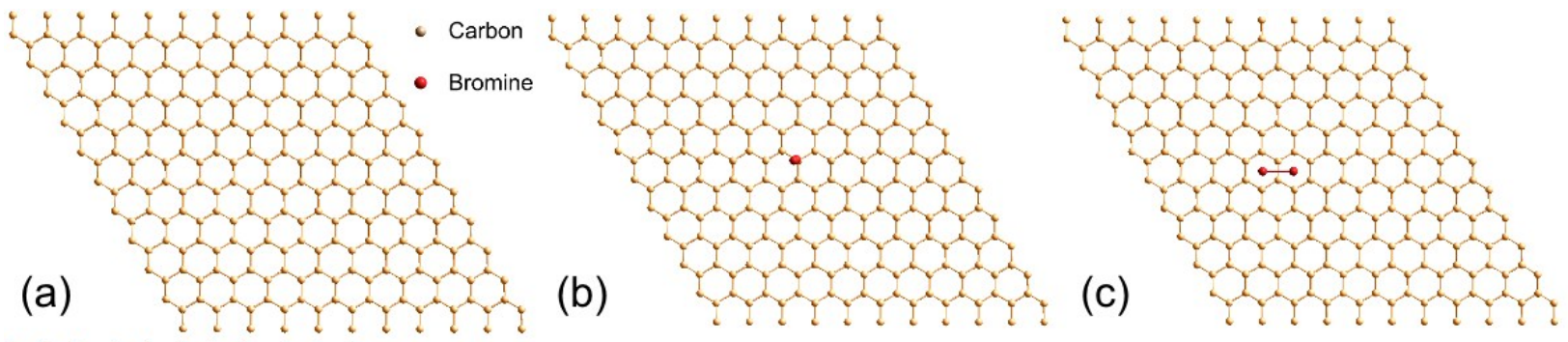

(d)
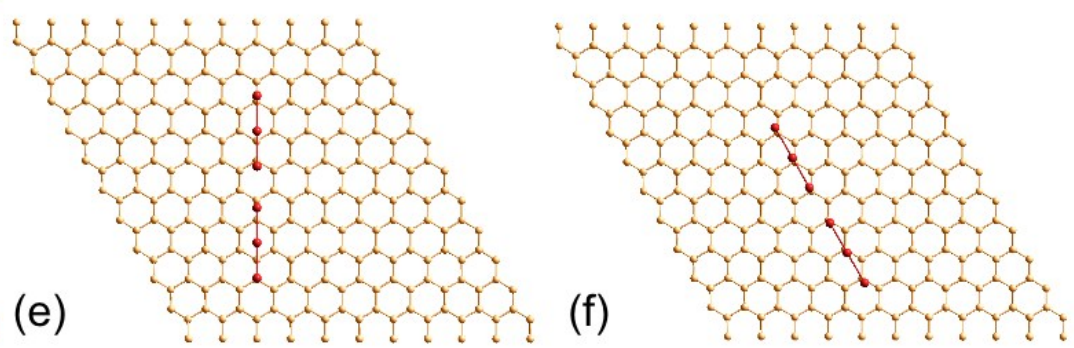

Fig. S1 Optimized geometries of graphene supercell (a), $\mathrm{Br}_{2}$ oriented perpendicular (b) and parallll (c) to graphene sheet, $\mathrm{Br}_{3}(\mathrm{~d})$, and $\mathrm{Br}_{6}(\mathrm{i}, \mathrm{j})$ over graphene sheet.

Table S1 Comparison of stretching frequencies of $\mathrm{Br}_{3}$ over graphene obtained using LDA within spin-averaged and spin-polarized approaches.

\begin{tabular}{|l|l|l|l|}
\hline $\mathrm{kt}$ & $\mathrm{S}_{\mathrm{av}} / \mathrm{S}_{\mathrm{pol} .}$ & $\mathrm{E}^{\text {tot }}$ spin av. ${ }^{-E^{\text {tot }}}$ spin pol. & $v_{\text {spin. av. }} / v_{\text {spin pol. }}$ \\
\hline 0.04 & $0 / 0.002$ & $0 \mathrm{eV}$ & $v_{3=164 / 164 \mathrm{~cm}^{-1} ; v_{3}^{a}=220 / 220 \mathrm{~cm}^{-1}}$ \\
\hline 0.01 & $0 / 1$ & $0.1 \mathrm{eV}$ & $\begin{array}{c}s \\
v_{3}\end{array}$ \\
\hline
\end{tabular}

Table S2 Dependence of calculated parameters for the $\mathrm{Br}_{2}$ in parallel orientation to graphene sheet on the size of unit cell and k-point grid.

\begin{tabular}{|c|c|c|c|}
\hline graphene cell size & $k$-point grid & $Q_{B r_{2}}(e)$ & $v_{2}^{S}\left(\mathrm{~cm}^{-1}\right)$ \\
\hline $4 \times 4$ & $1 \times 1 \times 1$ & -0.09296 & 309.2126 \\
\hline $4 \times 4$ & $9 \times 9 \times 1$ & -0.161316 & 258.1 \\
\hline $5 \times 5$ & $1 \times 1 \times 1$ & -0.08489 & 310.97708 \\
\hline $6 \times 6$ & $1 \times 1 \times 1$ & -0.084 & 318.84834 \\
\hline $7 \times 7$ & $1 \times 1 \times 1$ & -0.14167 & 255.47528 \\
\hline $8 \times 8$ & $1 \times 1 \times 1$ & -0.13815 & 256.54681 \\
\hline $9 \times 9$ & $1 \times 1 \times 1$ & -0.09754 & 291.92995 \\
\hline $10 \times 10$ & $1 \times 1 \times 1$ & -0.18717 & 239.85602 \\
\hline $11 \times 11$ & $1 \times 1 \times 1$ & -0.18168 & 233.89082 \\
\hline
\end{tabular}




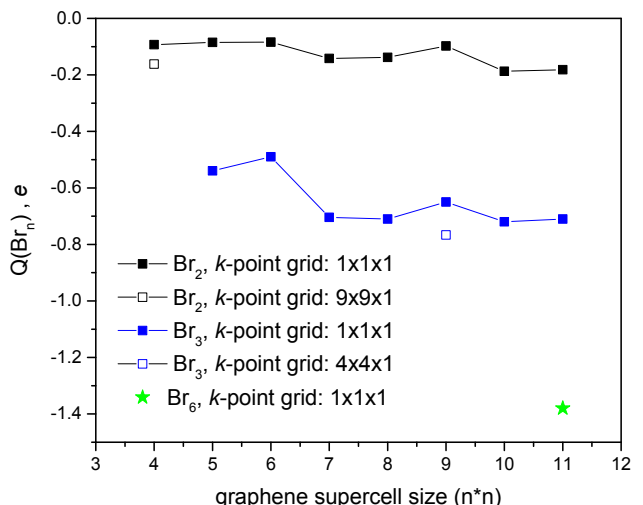

(a)

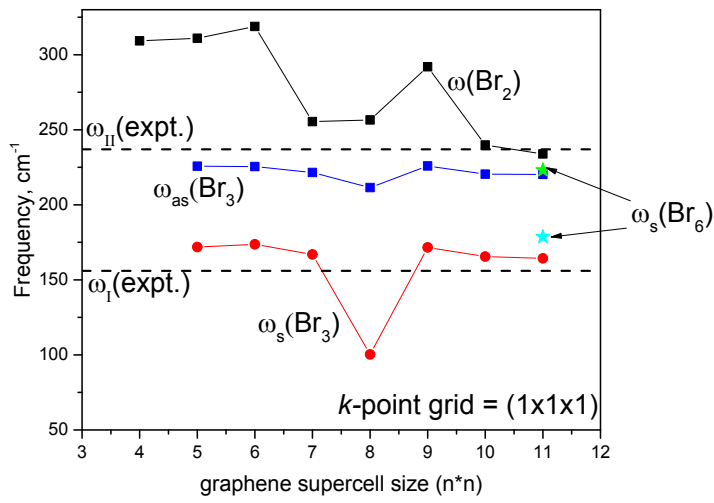

(b)

Fig. S2 Variation in calculated charge (a) and stretching frequencies (b) of $\mathrm{Br}_{2}, \mathrm{Br}_{3}$ and $\mathrm{Br}_{6}$ located over graphene sheet with the size of graphene supercell and k-point grid. Dashed lines in (b) correspond to peak I and II of experimental Raman spectra of brominated graphite and bromineintercalated fluorinated graphites (see Fig. 1).
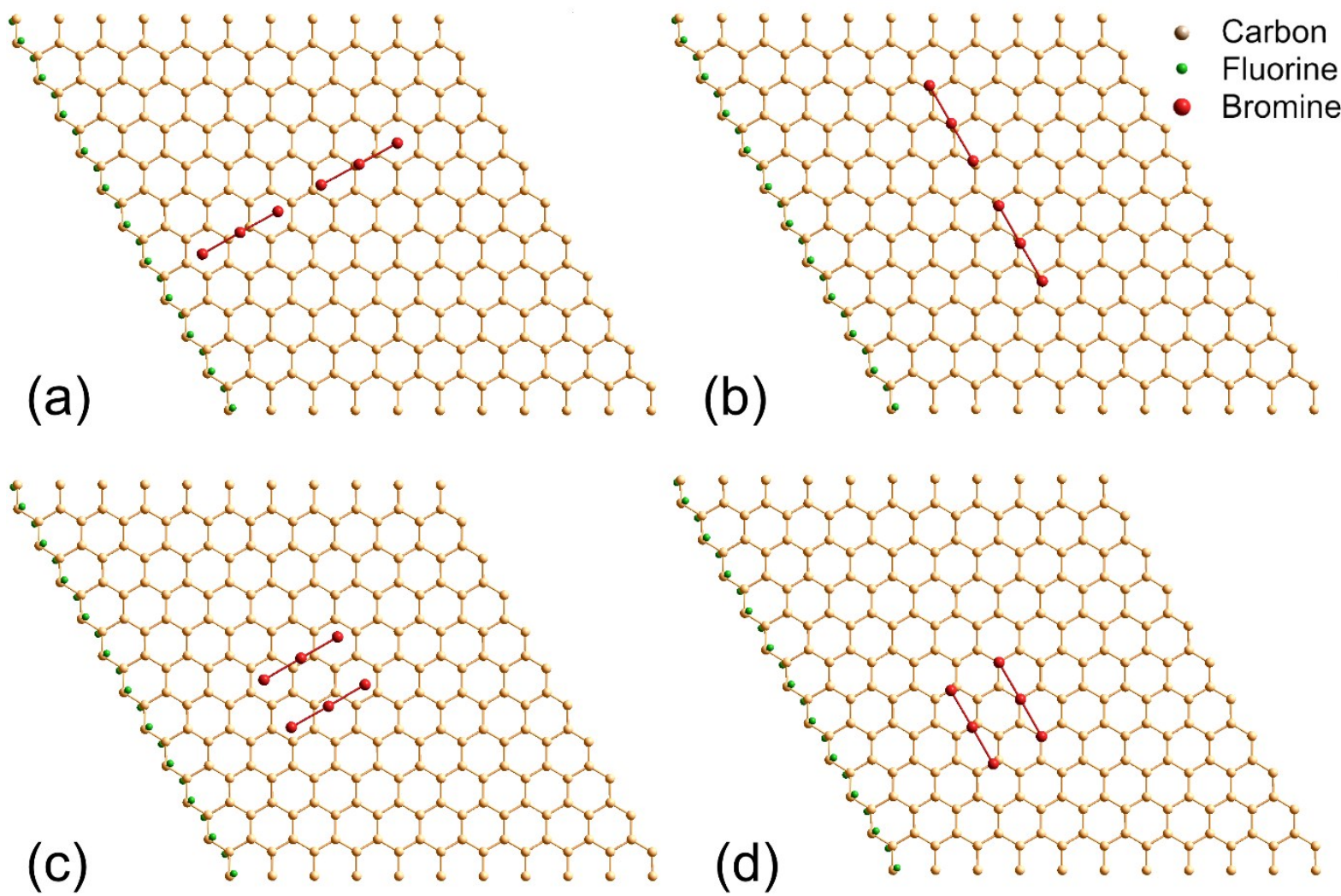

Fig. S3 Optimized geometries of metastable structures of $\mathrm{Br}_{6}$ over partially fluorinated graphene sheet. 
Table S3 Calculated binding energy $E_{b}$ per one bromine atom (eV), charge transfer $\mathrm{Q}_{\mathrm{Br} 6}(\mathrm{e})$, and symmetrical stretching $\mathrm{Br}-\mathrm{Br}$ frequencies $\omega_{s}\left(\mathrm{~cm}^{-1}\right)$ for the $\mathrm{Br}_{6}$ over partially fluorinated graphene (see Fig. S3).

\begin{tabular}{|c|c|c|c|}
\hline & $E_{b} / \mathrm{Br}(\mathrm{eV})$ & $Q_{B r_{6}}$ & $v_{3}^{S}-v_{3}^{S} / v_{3}^{a}-v_{3}^{a}\left(\mathrm{~cm}^{-1}\right)$ \\
\hline (a) & -0.359 & -1.25 & $162.9 / 227.3$ \\
\hline (b) & -0.360 & -1.28 & $159.6 / 225.2$ \\
\hline (c) & -0.359 & -0.65 & $179.0 / 230.1$ \\
\hline (d) & -0.358 & -0.59 & $181.9 / 231.1$ \\
\hline
\end{tabular}

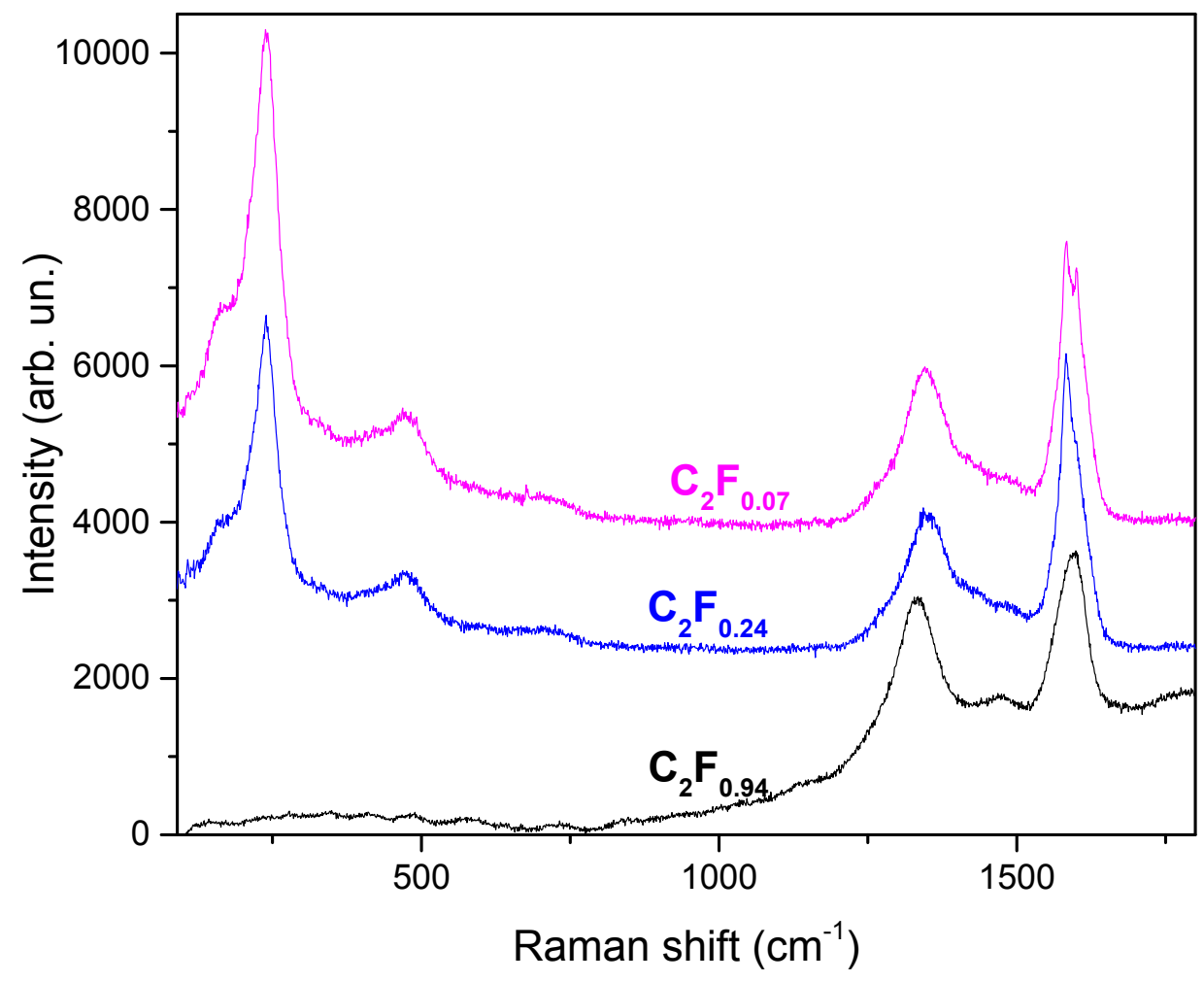

Fig. S4 Raman spectra taken at $514 \mathrm{~nm}$ for graphite intercalation compounds $\left(\mathrm{C}_{2} \mathrm{~F}_{\mathrm{x}}-\mathrm{Br}\right)$ synthesized without additional treatment with $\mathrm{Br}_{2}$ vapors. 